DOE/ER/61037-4

Distribution Category UC-60

\title{
UPPER OCEAN MODEL OF DISSOLVED ATMOSPHERIC GASES
}

\author{
FINAL REPORT \\ FOR THE PERIOD \\ 1 AUGUST 1991 - 31 MAY 1995
}

Dr. Rebecca Schudlich and Dr. Steven Emerson

\author{
University of Washington \\ Box 357940 \\ Seattle, WA 98195
}

\author{
Prepared for the \\ U.S. Department of Energy \\ Office of Energy Research \\ Under grant DE-FG06-90ER61037
}

\section{DISCLAIMER}

This report was prepared as an account of work sponsored by the United States Government. Neither the United States nor any agency thereof, nor any of their employees, makes any warranty, express or implied, or assumes any legal liability or responsibility for the accuracy, completeness, or usefulness of any information, apparatus, or process disclosed, or represents that its use would not infringe privately owned rights. Reference herein to any specific commercial product, process, or service by trade name, mark, manufacturer, or otherwise does not necessarily constitute or imply its endorsement, recommendation, or favoring by the United States government or any agency thereof. The views and opinions of authors expressed herein do not necessarily state or reflect those of the United States government or any agency thereof.

RECEIVED 


\section{Contents}

Summary $\quad$...................................................................

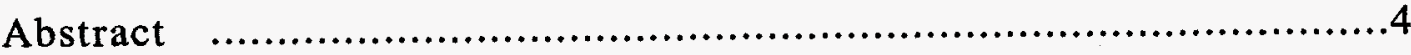

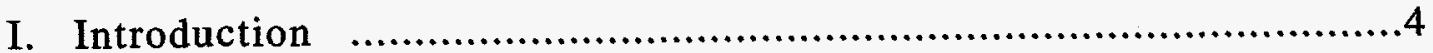

II. Results

A. The Model......................................................5

B. Meteorological and Oceanographic Data at station ALOHA..................6

C. Summary of Modelling Results..........................................6

References.............................................................. 8

\section{DISCLAIMER}

This report was prepared as an account of work sponsored by an agency of the United States Government. Neither the United States Government nor any agency thereof, nor any of their employees, makes any warranty, express or implied, or assumes any legal liability or responsibility for the accuracy, completeness, or usefulness of any information, apparatus, product, or process disclosed, or represents that its use would not infringe privately owned rights. Reference herein to any specific commercial product, process, or service by trade name, trademark, manufacturer, or otherwise does not necessarily constitute or imply its endorsement, recommendation, or favoring by the United States Government or any agency thereof. The views and opinions of authors expressed herein do not necessarily state or reflect those of the United States Government or any agency thereof. 
RESEARCH SUMMARY

Project Title: UPPER OCEAN MODEL OF DISSOLVED ATMOSPHERIC GASES

Investigators: Rebecca Schudlich and Steve Emerson

University of Washington School of Oceanography

Grant Number: DE-FG06-90ER61037

Disbursement Period: 09/01/91-05/30/95

Research Objectives: To quantify oceanic photosynthesis and respiration in the subtropical Pacific Ocean, and understand the physical processes governing the behavior of dissolved gases in the ocean.

Product: Three research papers: two appearing in the oceanographic research journals Deep-Sea Research and Journal of Geophysical Research and a third submitted to Global Biogeochemical Cycles; one conference proceeding appearing in Proceedings of the International Council for Exploration of the Sea; and several presentations at international research conferences.

Approach: We determined the concentrations of the major atmospheric gases (nitrogen, oxygen, and argon) in surface waters at station ALOHA in the subtropical Pacific Ocean in conjunction with the National Science Foundation's Joint Global Ocean Flux Study (JGOFS) Hawaiian Ocean Time-Series project during the years 1990 and 1992. Under DOE grant DE-FG06-90ER61037 we formulated a model of the seasonal cycle of dissolved gases in the upper ocean. To quantify the biological and physical contributions to the oxygen fields, we used data assimilation techniques to combine data with the numerical model, thereby estimating net community oxygen production and carbon dioxide uptake in the subtropical ocean. Since the subtropical ocean supports an oligotrophic ecosystem which is typical of $70 \%$ of the world ocean, our results may be generalized to global scales.

Results: Our results suggest that in the euphotic zone (the region of the ocean where photosynthesis occurs), net community oxygen production consumption is 1.0 to 2.0 moles of gas per square meter of ocean surface per year. This agrees roughly with estimates based on the carbon flux into the deep ocean, verifying for the first time the utility of dissolved gases as chemical tracers of biological processes in the ocean. In addition, our research has demonstrated that the process of bubble injection by surface waves is essential to reproduce observed levels of gas saturation with the model. Thus it is vital to include bubble injection in numerical simulations of dissolved gases. 


\section{ABSTRACT}

This report summarizes results from three years of funding for a modelling study of processes controlling the distribution of metabolic chemical tracers in surface waters. We determined concentrations of the gases $\mathrm{O}_{2}, \mathrm{Ar}, \mathrm{N}_{2}$, and the stable isotope ratio $\left({ }^{18} \mathrm{O} / 16 \mathrm{O}\right)$ of molecular oxygen in surface waters at Station ALOHA in conjunction with the Global Ocean Flux Study (GOFS) Hawaiian Ocean Time-series project during the years 1989-90 and 1992-93 (NSF OCE-8820380). Under DOE grant DE-FG06-90ER61037 we have incorporated chemical tracers into an existing ocean mixed-layer model to simulate the physical processes controlling the distribution and seasonal cycle of dissolved gases in the upper ocean. The broad background of concurrent chemical, physical, and biological measurements at station ALOHA provides enough redundancy of "ground truth" to assess the model's accuracy. Biological oxygen production estimated from modeled chemical tracers agrees with estimates based on measurements of carbon fluxes into the deep ocean and nitrate fluxes into the upper ocean during 1989-90 and 1992-93, verifying for the first time the utility of chemical tracers for determining biological fluxes in the ocean. Our results suggest that in the euphotic zone (the upper $100 \mathrm{~m}$ of the ocean), the net biological $\mathrm{O}_{2}$ production is $1.0-2.0$ moles $\mathrm{m}^{-2} \mathrm{yr}^{-1}$. Inert gas $\left(\mathrm{Ar}, \mathrm{N}_{2}\right)$ supersaturation levels show that air and bubble injection are important modes of air-sea gas transfer in the Station ALOHA region. The results from this work appear in Emerson et al. (1995), Schudlich and Emerson (1996), and Schudlich et al. (1996).

\section{INTRODUCTION}

The flux of carbon dioxide from the atmosphere to the ocean and the flux of organic matter to the ocean interior are controlled by the same processes that maintain the flux of nutrients and metabolic products $(\mathrm{C}, \mathrm{N}, \mathrm{P}, \mathrm{O})$ through the euphotic zone of the ocean. Since nitrogen is usually the nutrient that limits phytoplankton growth, the rate of supply of $\mathrm{N}$ into the euphotic zone has been coined new production (Eppley and Peterson, 1979; Dugdale and Goering, 1967) and is a convenient estimate of the net flux of nutrients through the surface ocean. This mass balance concept naturally applies to all elements that flow through the biological cycle. Because recycling of organic matter within the euphotic zone supplies nitrogen in the form of dissolved ammonia, and the nitrogen flux from below the mixed layer is in the form of nitrate, the fraction of primary production that is "new" is often measured as relative uptake rates of ${ }^{15} \mathrm{~N}$-labled nitrate and ammonia. Traditional 
${ }^{14} \mathrm{C}$ uptake incubations are believed to measure a value similar to that determined by the rate of incorporation of both $\mathrm{NO}_{3}{ }^{-}$and $\mathrm{NH}_{4}{ }^{+}$which is between the rates of net and gross primary production (Bender et al., 1987).

In the past decade, several workers have calculated new production rates using dissolved oxygen as a tracer in the euphotic zone (Shulenberger and Reid, 1981; Jenkins, 1982; Jenkins and Goldman, 1985; Emerson, 1987; Craig and Hayward, 1987; Musgrave et al., 1988; and Spitzer and Jenkins, 1989). The fraction of primary production production that escapes the upper ocean is proportional to the biologically produced flux of oxygen out of the euphotic zone and carbon dioxide out of the atmosphere. If the physical processes of gas exchange with the atmosphere and transport between the mixed layer and subsurface waters can be estimated along with the depth dependence of $\mathrm{O}_{2}$ production, the rate of new production is calculable from dissolved gas measurements and stoichiometric ratios relating the metabolic tracers.

In the oxygen balance studies completed to date (Spitzer and Jenkins, 1989; Musgrave et al., 1988; Thomas et al., 1991; Garcon et al., 1992; and Archer et al., 1992), all have used mixed layer models capable of reproducing the density field. New production in these studies was treated as an oxygen source of unknown depth dependence. The drawbacks of this work is that many of these studies used physical forcing from historical data, and there were no simultaneous biological and sediment trap measurements to compare with model predictions. In the present work we address both of these shortcomings, using contemporaneous meteorological forcing when possible and validating model simulations against measured chemical tracers and hydrography.

\section{RESULTS}

\section{A. The Model}

We adapted the 1-dimensional "PWP" upper ocean model (Price, Weller and Pinkel, 1987) to simulate the behavior of dissolved atmospheric gases $\mathrm{O}_{2}, \mathrm{Ar}$ and $\mathrm{N}_{2}$. The model simulates the structure and depth of the ocean surface mixed layer based on surface heat and momentum fluxes and Richardson number criteria. Gas exchange with the atmosphere is parameterized using the method of Liss and Merlivat (1980) and air injection by breaking waves is simulated based on the findings of Spitzer and Jenkins (1989). 
Exchange between the surface ocean and the deeper ocean is represented by a constant eddy diffusivity. We simulated the upper $300 \mathrm{~m}$ of the ocean at station ALOHA of the Hawaiian Ocean Time-series program, using a vertical resolution of $2 \mathrm{~m}$. Simulations are integrated forward in time with a time step of 3 hours over a period of three (repeating) years, and the third year is compared with measured oceanographic conditions at ALOHA in 1990.

\section{B. Meteorological and Oceanographic Data at station ALOHA}

Wind stress and air/sea heat fluxes used to force the model are estimated from bulk meteorological measurements at an NDBC weather buoy near station ALOHA, using the bulk flux methods of Liu et al. (1979) and Large and Pond (1981). Solar radiation is based on satellite measurements made at station ALOHA in 1983-84. Satellite measurements of the solar radiation at ALOHA in 1990 have just become publicly available and will be incorporated into our approach shortly.

Our simulations are verified against our dissolved gas measurements (NSF OCE8820380) and observations of upper ocean hydrography and biological parameters made by the Hawaiian Ocean Time-series program (Chiswell et al., 1990; Winn et al., 1992). These measurements illustrate the annual warming of the surface ocean and the resulting degassing of dissolved atmospheric gases. A late summer maximum in biological oxygen production is apparent in the observed subsurface accumulation of oxygen and depletion of ${ }^{16} \mathrm{O}$ (negative values of $\delta^{18} \mathrm{O}$ ).

\section{Summary of Modelling Results}

We have achieved both of our major goals for this study: (1) to assess the ability of the 1-dimensional PWP model to reproduce conditions at station ALOHA, and (2) to assess the utility of chemical tracers for estimating biological fluxes in the upper ocean. In addition to these original goals, we have also used the modelling approach of (1) above to assess the role of bubbles in air-sea gas transfer.

The main results of Emerson et al. (1995) are annual rates of net biological oxygen production in the euphotic zone and respiration in the upper thermocline of the subtropical North Pacific. These were determined using mass balances of oxygen, argon, and nitrogen measured at U.S. JGOFS Hawaiian Ocean Time-series station ALOHA. We found that net evasion of nitrogen and argon to the atmosphere caused by warming of surface waters is 
balanced by supply primarily from cross-isopycnal transport. Mixing rates between the euphotic zone and the top of the permanent thermocline required to balance the inert gas flux are $1-2 \mathrm{~cm}^{2} \mathrm{~s}^{-1}$. Application of mixing rates derive from the inert gas mass balances to the oxygen field yields a net annual euphotic zone production rate of $1.4 \pm 1.0$ moles $^{\mathrm{O}_{2} \mathrm{~m}^{-2}}$ $\mathrm{yr}^{-1}$, one half of which is lost to the atmosphere, with most of the rest mixed into the top of the thermocline. Since cross-isopycnal gradients of dissolved organic carbon (DOC) are about half that of oxygen, we estimate that at least one quarter of the carbon flux out of the euphotic zone is via DOC. Because surface ocean dissolved organic matter has a relatively high $\mathrm{C} / \mathrm{N}$ ratio, the stoichiometry among $\mathrm{O}_{2}, \mathrm{C}$, and inorganic $\mathrm{N}$ in the upper ocean should be different than that observed in deeper waters.

In Schudlich et al. (1996), we also determined the net annual biological productivity (photosynthesis minus respiration) at Hawaiian Ocean Time-series station ALOHA, again by using a mass balance approach. However here we formulated a more complicated and realistic model of the important physical processes affecting dissolved atmospheric gases $\left(\mathrm{Ar}, \mathrm{N}_{2}, \mathrm{O}_{2}\right)$ in the upper ocean. Again, no biological processes are included in the model. We determine the net biological production of oxygen, via data assimilation methods, as the difference between the abiotic simulation of $\mathrm{O}_{2}$ and measurements of oxygen at station ALOHA made in 1989-1990. By this method, we find a net production of $1.6 \pm 0.5 \mathrm{~mol}$ $\mathrm{O}_{2} \mathrm{~m}^{-2} \mathrm{yr}^{-1}$ in the euphotic zone and $0.7 \pm 0.3 \mathrm{~mol} \mathrm{O}_{2} \mathrm{~m}^{-2} \mathrm{yr}^{-1}$ in the upper $150 \mathrm{~m}$. This estimate of euphotic zone net productivity is similar to that found by Emerson et al., 1995, and the $150-\mathrm{m}$ value is somewhat lower than that determined from the carbon flux at $150 \mathrm{~m}$ (Winn et al., 1992), though within its error range. This data assimilation method of estimating net biological oxygen production is quite sensitive to the parameterization of air injection, which we optimize by tuning air injection to the surface $\mathrm{N}_{2}$ saturation, and less sensitive to most other processes. This study is one of the first uses of data assimilation techniques to estimate biological quantities in the ocean.

In Schudlich and Emerson (1996), we use our one-dimensional model of mixed layer dynamics to examine the roles of heat flux, gas exchange, and bubble processes in producing nitrogen and argon gas supersaturation in the surface subtropical Pacific ocean at U.S. JGOFS Station ALOHA. We demonstrated that bubble processes are essential to produce observed supersaturation levels. $N_{2} / A r$ ratios at Station ALOHA indicate that air injection of small (totally-dissolving) bubbles is the dominant process during the summer, but during the fall and winter larger (partially-dissolving) bubbles become more important. 
Given current measurement techniques, it is possible to distinguish between small and large bubbles when inert gas supersaturations are high $(>2 \%)$ and when the dynamic range in predicted inert gas ratios is largest (late fall). Existing models which parameterize bubble dynamics as a function of wind speed do not reproduce the high observed supersaturations that this study indicates are influenced by large bubble processes.

\section{REFERENCES}

Archer, D., S. Emerson, T. Powell, and C.S. Wong, 1992. Numerical prediction of $\mathrm{pCO}_{2}$ at the sea surface at Weathership Station Papa, in preparation.

Bender, M., K. Grande, K. Johnson, J. Marra, P.J. Leb. Williams, J. Siebunth, M. Pilson, C. Langdon, G. Hitchcook, J. Orchardo, C. Hunt, P. Dunaghay, and K. Heinemann, 1987. A comparison of four methods for determining planktonic community respiration. Oceanogr. 32, 1085-1099.

Chiswell, S., E. Firing, D. Karl, R. Lukas, and C. Winn, 1990. Hawaii Ocean Timeseries Data Report 1, 1988-1989. SOEST Tech. Rep. \#1, Univ. of Hawaii, 269 pp.

Craig, H. and T. Hayward, 1987. Oxygen supersaturation in the ocean: biological versus physical contributions. Science 235, 199-202.

Dugdale, R., and Goering, 1967. Uptake of new and regenerated forms of nitrogen in primary productivity. Limnol. Oceanogr. 12, 196-206.

Emerson, S., 1987. Seasonal oxygen cycles and biological new production in surface waters of the subarctic Pacific ocean. J. Geophys. Res. 92, 6535-6544.

Emerson, S., P. Quay, C. Stump, D. Wilbur, and R. Schudlich, 1993. Determining primary production from the mesoscale oxygen field. In: Proceedings of the International Council for Exploration of the Sea (ICEA), La Rochel, France, ICEA Mar. Sci. Symp. 197, 196-206.

Emerson, S., P. Quay, C. Stump, D. Wilbur, and R. Schudlich, 1995. Chemical tracers of productivity and respiration in the subtropical Pacific ocean. Journal of Geophysical Research, 100, 15873-15887.

Eppley, R. W. and B. J. Peterson, 1979. Particulate organic matter flux and planktonic new production in the deep ocean. Nature 282, 677-680.

Garcon, V. C., F. Thomas, C. S. Wong, and J. F. Minster, 1991. Gaining insight into the seasonal variability of $\mathrm{CO}_{2}$ at Ocean Station Papa using an upper ocean model. Deep Sea Res., submitted. 
Jenkins, W. J., 1982. Oxygen utilization rates in the North Atlantic subtropical gyre and primary production in oligotrophic systems. Nature 300, 246-248.

Jenkins, W. J. and J. Goldman, 1985. Seasonal oxygen cycling and primary production in the Sargasso Sea. J. Mar. Res. 43, 465-491.

Large, W.G. and S. Pond, 1981. Open ocean momentum flux measurements in moderate to strong winds. J. Phys. Oceanogr. 11, 324-336.

Liss, P. S. and L. Merlivat, 1986. Air-sea gas exchange rates: Introduction and synthesis; in The role of air-sea gas exchange in geochemical cycling, edited by Baut-Menard and D. Reidel, 113-127.

Liu, T., K. Katsaros, and E. Businger, 1979. Bulk parameterization of air-sea exchanges of heat and water vapor including the molecular constraints at the interface. $J$. Atmos. Sci. 36, 1722-1735.

Musgrave, D., J. Chou, and W. Jenkins, 1988. Application of a model of upper-ocean physics for studying seasonal cycles of oxygen. J. Geophys. Res. 93, 1567915700 .

Price, J.F., R.A. Weller, and R. Pinkel, 1986. Diurnal cycling: observations and models of the upper ocean response to diurnal heating cooling, and wind mixing. J. Geophys. Res. 91, 8411-8427.

Schudlich, R., S. Emerson, P. Quay, and C. Stump, 1996. Net community production in the subtropical Pacific ocean: estimates from modeling and data assimilation of dissolved gases. Global Biogeochemical Cycles, submitted.

Schudlich, R., and S. Emerson, 1996. Gas saturation in the surface ocean: The roles of heat flux, gas exchange, and bubbles. To appear in Deep-Sea Research II, vol. 43, no. 1 .

Shulenberger, E. and J. L. Reid, 1981. The Pacific shallow oxygen maximum, deep chlorophyll maximum and primary productivity, reconsidered. Deep Sea Res. 28, 901-919.

Spitzer, W. and W. Jenkins, 1989. Rates of vertical mixing, gas exchange and new production: Estimates from seasonal gas cycles in the upper ocean near Bermuda. $J$. Mar. Res. 47, 169-196.

Thomas, F., J. F. Minster, P. Gaspar, and Y. Gregoris, 1991. Comparing the behavior of two ocean surface model in simulating dissolved $\mathrm{O}_{2}$ at Ocean Weather Station Papa. Deep Sea Res., submitted.

Winn, C., S. Chiswell, E. Firing, D. Karl, and R, Lukas, 1992. Hawaii Ocean Timeseries Data Report 2, 1990. SOEST Tech. Rep. \#92-1, Univ. of Hawaii, 175 pp. 